\title{
Optimalisasi Ketebalan Timbal Untuk Mendapatkan Kualitas Citra Guna Mendukung Verifikasi Pada Pesawat Teleterapi ${ }^{60} \mathrm{Co}$
}

\author{
Maimunah $^{1}$, Riyatun ${ }^{2}$, Suharyana $^{3}$, Muhtarom ${ }^{4}$ \\ 1, 2, 3 Program Studi S1 Fisika, Universitas Sebelas Maret, Jl. Ir. Sutami no 36 Kentingan Surakarta \\ ${ }^{4}$ RSUD Dr.Moewardi, Jl. Kolonel Sutarto, Jebres, Kec. Jebres, Kota Surakarta 57126 \\ Email : maimunah@student.uns.ac.id
}

\begin{abstract}
The quality of radiotherapy images supports the steps of verifying the accuracy of the dose and verifying the geometry, for example the area of field and the accuracy of the patient's position. Radiotherapy image capture requires a radiation filter that is thick enough, due to the strong radiation dose from the ${ }^{60}$ Co source. Lead thickness optimization is needed so that the irradiation recording on the Imaging Plate produces an adequate image to be scanned via Computed Radiography. Analysis using Dose.Lab 4.1 software with the Region of Interest technique so that the Mean Gray Value (MGV) is obtained and the contrast is obtained by the Contrast to-Noise Ratio (CNR) analysis. Standard exposure of 2 seconds and 3 seconds at the collimation area $(10 \times 10) \mathrm{cm}^{2}$, using a $1,8 \mathrm{~cm}$ Pb filter shows the most optimal image. The thicker the $\mathrm{Pb}$, the greater the $M G V$ value, which indicates high radiation absorption. $M G V$ will decrease with the addition of filters. The optimal thickness of Pb in decreasing the dose rate for irradiation of 1, 2 and 3 seconds, respectively, was starting from 2,7 cm and $4,5 \mathrm{~cm}$, meanwhile for 3 seconds there is no optimal lead thickness.
\end{abstract}

Keywords: Lead, Image Quality, Contrast to Noise Ratio

\begin{abstract}
Abstrak: Kualitas citra radioterapi mendukung tahapan verifikasi ketepatan dosis dan verifikasi geometri misalnya luas lapangan dan ketepatan posisi pasien. Pengambilan citra radioterapi memerlukan filter radiasi yang cukup tebal, disebabkan oleh kuatnya dosis radiasi dari sumber ${ }^{60}$ Co. Diperlukan optimasi tebal timbal agar rekaman penyinaran pada Imaging Plate menghasilkan citra yang memadai untuk dipindai melalui Computed Radiography. Analisa menggunakan Software Dose.Lab 4.1 dengan teknik Region Of Interest sehingga diperoleh Mean Gray Value(MGV) dan kontras diperoleh dengan analisa Contrast to-Noise Ratio (CNR). Eksposure standar 2 detik dan 3 detik pada luas kolimasi $(10 \times 10) \mathrm{cm}^{2}$, pemakaian $1,8 \mathrm{~cm}$ filter $\mathrm{Pb}$ menunjukkan citra yang paling optimal. Semakin tebal $\mathrm{Pb}$ maka nilai MGV semakin besar yang menunjukkan serapan radiasi tinggi. MGV akan menurun dengan penambahan filter. Tebal $\mathrm{Pb}$ yang optimal dalam menurunkan laju dosis untuk penyinaran 1 dan 2 detik masingmasing adalah mulai dari $2,7 \mathrm{~cm}$ dan $4,5 \mathrm{~cm}$, sedangkan untuk 3 detik tidak ada tebal $\mathrm{Pb}$ yang optimal.
\end{abstract}

Kata kunci: Timbal, Kualitas Citra, Contrast to-Noise Ratio

\section{PENDAHULUAN}

Radioterapi adalah suatu tindakan menggunakan radiasi pengion dalam pengoperasiannya yang ditujukan pada pasien penderita kanker. Pesawat Teleterapi ${ }^{60} \mathrm{Co}$ merupakan salah satu alat yang diterapkan pada pasien kanker menggunakan sumber radioaktif ${ }^{60} \mathrm{Co}$. Sumber ${ }^{60} \mathrm{Co}$ memancarkan 2 foton- $\gamma$ dengan energi masing-masing 1,17 MeV dan 1,33 MeV (Khan, 2014). 
Citra pada radioterapi digunakan pada tahap verifikasi. Citra dengan kualitas yang tinggi akan lebih mudah dibaca oleh mata sehingga meminimalkan terjadinya kesalahan. Akibatnya kesesuaian antara perencanaan dengan hasil verifikasi yang diperoleh dapat lebih akurat. Kualitas citra merupakan keseluruhan informasi yang dapat diberikan. Sebuah citra dikatakan memiliki kualitas gambar yang tinggi jika memiliki semua informasi yang dibutuhkan dalam memastikan sebuah kanker atau tumor (Wahdayuni, 2017). Kualitas citra meliputi densitas, kontras, ketajaman dan distorsi (Sparzinanda dkk, 2017).

Kontras film adalah perbedaan densitas optik antara dua area dalam gambar. Kontras salah satunya dipengaruhi oleh hamburan radiasi. Apabila suatu objek menyerap lebih sedikit radiasi dibandingkan dengan jaringan di sekelilingnya maka akan terpancar bayangan negatif yang muncul sebagai bayangan yang gelap pada film radiografi. Nilai kontras juga dipengaruhi oleh koefisien atenuasi dari bahan yang dilewati radiasi- $\gamma$ (Pardede and Setiawati, 2014). Kontras radiograf dalam citra digital dapat dianalisis secara kuantitatif dengan metode Contrast to Noise Ratio (CNR) yang dapat diperoleh dengan menentukan ROI atau area yang dianalisa. Cara untuk menentukan CNR yaitu

$$
C N R=\left|\frac{S_{A}-S_{B}}{\sigma_{0}}\right|
$$

Berdasarkan persamaan di atas, $S_{A}$ merupakan mean ROI objek, $S_{B}$ adalah mean ROI background, dan $\sigma_{0}$ yaitu standar deviasi background (Aprilina, 2018).

Radiasi hambur merupakan hamburan compton yang dihasilkan oleh interaksi radiasi- $\gamma$ dan elektron bebas dalam bahan. Banyaknya kuantitas radiasi hambur dinyatakan dengan fraksi hambur yaitu perbandingan antara intensitas sekunder, $I_{S}$ dan intensitas total radiasi yang menembus material, $I_{s}+I_{p}, I_{p}$ adalah intensitas primer, dirumuskan sebagai berikut

$$
S F=\frac{I_{S}}{I_{p}+I_{S}}
$$

Radiasi- $\gamma$ yang dihamburkan bahan perisai ada kalanya mengalami hamburan balik dan kembali bergabung dengan berkas utama, sehingga radiasi yang terukur lebih besar dibandingkan dengan radiasi yang terhitung. Terjadinya peristiwa tersebut dinamakan pertumbuhan radiasi atau Build Up Factor (Kristiyanti dkk, 2014).

$$
\frac{I}{I_{o}}=B e^{-\mu x}
$$

Timbal termasuk unsur golongan IV A dalam tabel periodik yang memiliki lambang $\mathrm{Pb}$ dan nomor atom 82. Timbal merupakan logam berat dengan tingkat kerapatan tinggi yaitu 11,34 $\mathrm{g} / \mathrm{cm}^{3}$ sehingga jangkauan elektron dalam $\mathrm{Pb}$ akan sangat pendek. Kerapatan tersebut jika dibandingkan dengan alumunium yaitu $2,7 \mathrm{~g} / \mathrm{cm}^{3}$ maka ketika radiasi-- $\gamma$ melewati timbal akan terjadi pelemahan radiasi- $\gamma$ yang lebih banyak sehingga $\mathrm{Pb}$ dapat digunakan untuk perisai radiasi- $\gamma$ (Rahma, 2016). Foton yang mengenai bahan mengakibatkan terjadinya interaksi yang terdiri dari proses hamburan, pemindahan maupun penyerapan energi radiasi ke dalam materi yang disinari. Berdasarkan energi radiasi yang diserap maka interaksi tersebut dibagi menjadi 3 proses absorpsi yaitu efek fotolistrik, hamburan compton, produksi pasangan (Febriani, 2013).

\section{METODE PENELITIAN}

Penelitian ini menggunakan data sekunder hasil penelitian yang dilakukan oleh Maharany (2019) di sub Laboratorium Fisika Universitas Sebelas Maret dan Instalasi Radioterapi RSUD Dr. Moewardi pada tahun 2019. Alat dan bahan yang digunakan dalam penelitian ini adalah perangkat keras berupa laptop dan perangkat lunak software Dose.Lab 4.1., Origin, Microsoft 
Excel. Data sekunder berupa citra hasil penyinaran yang berwarna keabuan. Citra diukur melalui software Dose.Lab 4.1 berdasarkan intensitas serapan MGV pada tiap ketebalan $\mathrm{Pb}$ dengan 3 kali pengulangan. Nilai MGV kemudian diolah untuk mendapatkan nilai kontras, radiasi hambur, dan laju dosis. Penentuan laju dosis dilakukan dengan penambahan faktor B. Selanjutnya dibuat grafik hubungan kontras terhadap ketebalan, dan laju dosis terhadap ketebalan. Kemudian ditentukan nilai tebal $\mathrm{Pb}$ optimal yang menghasilkan kualitas citra tinggi dan dapat ditentukan tebal $\mathrm{Pb}$ yang dapat menurunkan laju dosis setara penyinaran 1 detik.

\section{HASIL DAN PEMBAHASAN}

Tabel 1. Data Hasil Pengolahan Citra Penyinaran tanpa Filter

\begin{tabular}{cccc}
\hline Tebal Pb $(\mathrm{cm})$ & MGV 1 detik & MGV 2 detik & MGV 3 detik \\
\hline 0,18 & $(194,72 \pm 0,17)$ & & \\
0,9 & $(206,33 \pm 0,33)$ & & \\
1,8 & $(216,81 \pm 0,13)$ & $(149,69 \pm 0,020)$ & \\
2,7 & $(222,84 \pm 0,091)$ & $(175,13 \pm 0,13)$ & \\
3,6 & $(226,72 \pm 0,26)$ & $(192,12 \pm 0,13)$ & \\
4,5 & $(234,04 \pm 0,052)$ & $(210 \pm 0,58)$ & $(213,04 \pm 0,037)$ \\
5,4 & $(240,18 \pm 0,17)$ & $(220,99 \pm 0,0033)$ & $(218,14 \pm 0,14)$ \\
background & $(175,74 \pm 0,95)$ & $(136,02 \pm 0,79)$ & $(203,08 \pm 0,45)$ \\
\hline
\end{tabular}

Tabel 2. Data Hasil Pengolahan Citra Penyinaran 2 Detik dengan Filter

\begin{tabular}{cccc}
\hline Tebal Pb $(\mathrm{cm})$ & MGV 9 filter & MGV 10 filter & MGV 11 filter \\
\hline 0,18 & & & \\
0,9 & $(213,22 \pm 0,22)$ & $(92,39 \pm 0,47)$ & $(82,95 \pm 0,31)$ \\
1,8 & $(217,96 \pm 0,037)$ & $(138,59 \pm 0,079)$ & $(103,96 \pm 0,56)$ \\
2,7 & $(218,11 \pm 0,11)$ & $(152,66 \pm 0,76)$ & $(182,68 \pm 0,34)$ \\
3,6 & $(221,24 \pm 0,24)$ & $(190,99 \pm 0,25)$ & $(196,77 \pm 0,90)$ \\
4,5 & $(223,10 \pm 0,097)$ & $(199,06 \pm 0,13)$ & $(198,02 \pm 0,20)$ \\
5,4 & $(225,96 \pm 0,034)$ & $(207,24 \pm 0,12)$ & $(210,42 \pm 0,22)$ \\
background & $(202,46 \pm 0,66)$ & $(23,92 \pm 1,79)$ & $(25,67 \pm 4,90)$ \\
\hline
\end{tabular}

Tabel 3. Data Hasil Pengolahan Citra Penyinaran 3 Detik dengan Filter

\begin{tabular}{cccc}
\hline Tebal $\mathrm{Pb}(\mathrm{cm})$ & MGV 9 filter & MGV 10 filter & MGV 11 filter \\
\hline 0,18 & & & \\
0,9 & $(156,73 \pm 0,16)$ & $(20,77 \pm 0,15)$ & $(20,96 \pm 0,037)$ \\
1,8 & $(169,71 \pm 0,91)$ & $(50,46 \pm 0,77)$ & $(21,41 \pm 0,64)$ \\
2,7 & $(183,42 \pm 0,55)$ & $(123,70 \pm 0,11)$ & $(113,99 \pm 0,38)$ \\
3,6 & $(191,20 \pm 0,13)$ & $(151,67 \pm 0,56)$ & $((145,87 \pm 0,45)$ \\
4,5 & $(199,99 \pm 0,33)$ & $(157,08 \pm 0,49)$ & $(146,87 \pm 0,052)$ \\
5,4 & $(208,89 \pm 0,60)$ & $(188,46 \pm 0,13)$ & $(187,43 \pm 0,45)$ \\
background & $(95,83 \pm 10)$ & $(23,99 \pm 1,18)$ & $(24,57 \pm 1,34)$ \\
\hline
\end{tabular}


Penelitian pertama setelah diperoleh nilai MGV yaitu penentuan kontras. Kontras dapat terjadi karena adanya perbedaan atenuasi radiasi oleh ketebalan tiap step nya. Berikut nilsi kontras ysng ditunjukksn melalui grafik pengaruh kontras terhadap ketebalan $\mathrm{Pb}$ seperti pada Gambar 1.

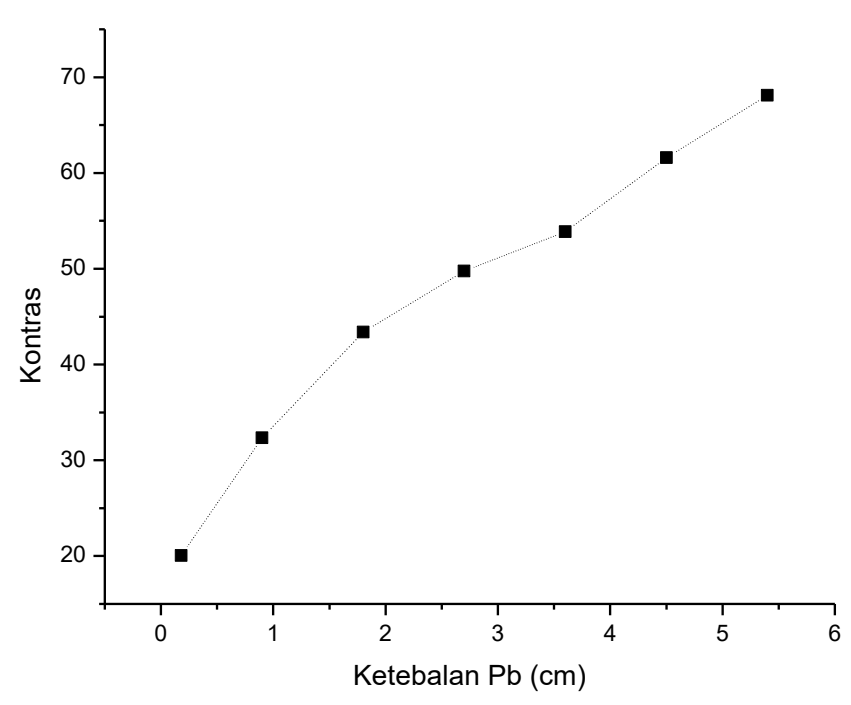

Gambar 1. Grafik Hubungan Kontras terhadap Ketebalan Pb pada Penyinaran 1 detik

Gambar 1. menunjukkan bahwa nilai kontras mengalami kenaikan ketika ketebalan $\mathrm{Pb}$ semakin bertambah. Hal ini dikarenakan perbedaan atenuasi pada masing-masing ketebalan $\mathrm{Pb}$. Pada ketebalan $\mathrm{Pb}$ yang semakin besar akan menyerap radiasi- $\gamma$ lebih besar. Pada citra nilai kontras yang semakin tinggi menampilkan warna yang semakin terang. Dan sebaliknya, nilai kontras yang semakin rendah akan menunjukkan warna yang semakin gelap. Timbal dengan ketebalan terbesar yaitu $5,4 \mathrm{~cm}$ mempunyai nilai kontras tertinggi yaitu $(68,09 \pm 0,18)$. Sedangkan $\mathrm{Pb}$ dengan ketebalan terkecil yaitu $0,18 \mathrm{~cm}$ akan menyerap paling sedikit radiasi sehingga mempunyai nilai kontras terendah $(20,06 \pm 0,18)$.

Berbeda dengan penyinaran 1 detik, penyinaran $\mathrm{Pb}$ dengan waktu 2 dan 3 detik tidak menampakkan semua step (7). Oleh karena itu diperlukan tambahan Pb sebagai filter untuk mereduksi radiasi- $\gamma$ yang sampai ke Imaging Plate. Berikut citra hasil penyinaran dengan penambahan $\mathrm{Pb}$.

$$
\begin{array}{lllllll}
1 & 2 & 3 & 4 & 5 & 6 & 7
\end{array}
$$

Gambar 2. Citra Penyinaran 1 Detik 


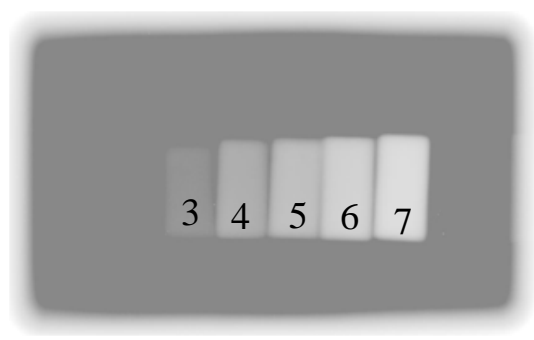

(a)

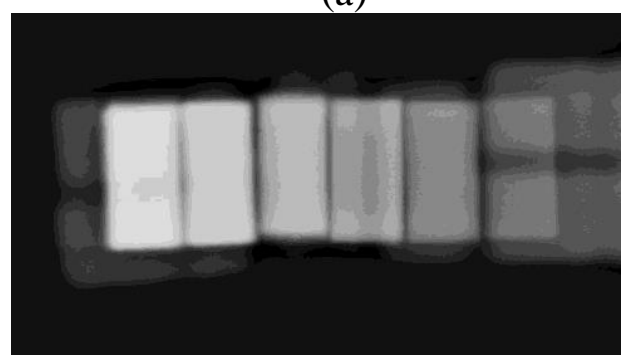

(b)

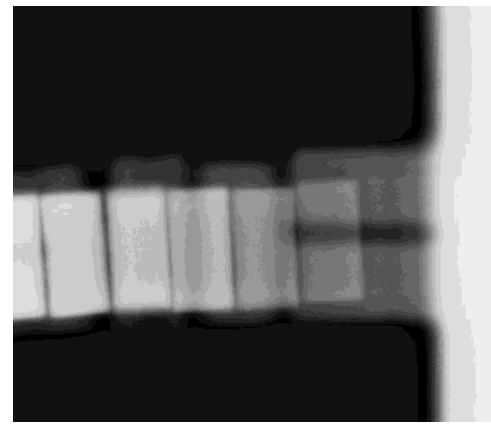

(c)

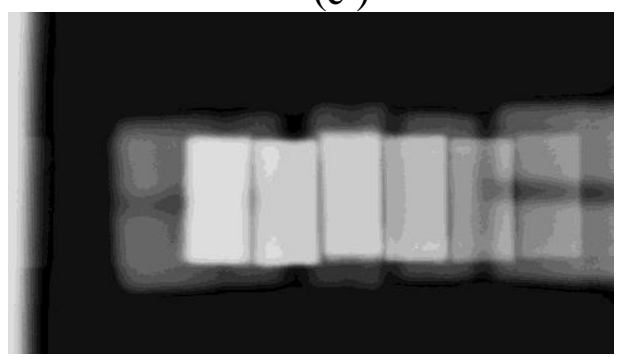

(d)

Gambar 3. Citra Penyinaran 2 Detik a) tanpa Filter b) dengan 9 Filter c) dengan 10 Filter d) dengan 11 Filter.

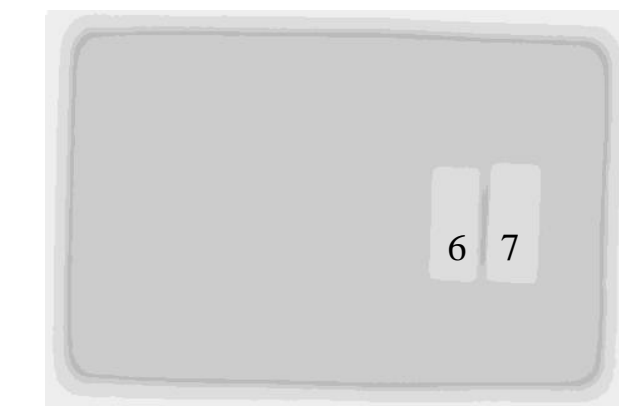

(a)

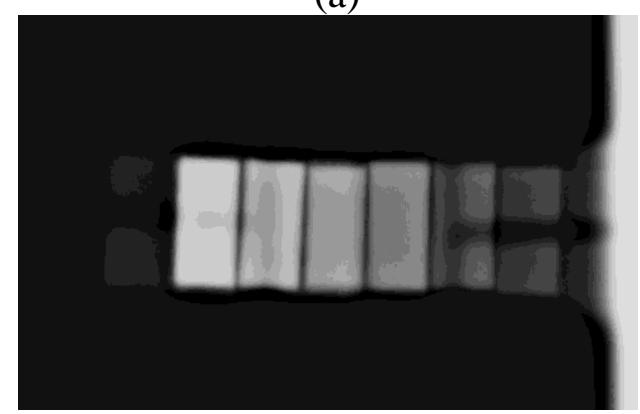

(c)

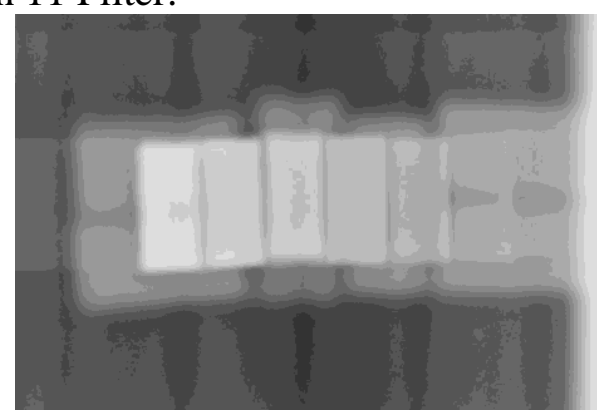

(b)

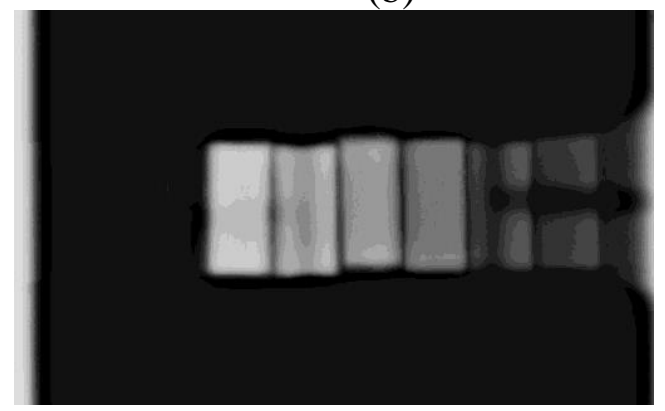

(d)

Gambar 4. Citra Penyinaran 3 Detik a) tanpa Filter b) dengan 9 Filter c) dengan 10 Filter d) dengan 11 Filter.

Citra yang dihasilkan pada penambahan 3 variasi filter belum mampu menampilkan semua step. Pada penyinaran 2 detik, menampilkan 1 tambahan step yaitu pada ketebalan $0,9 \mathrm{~cm}$. Pada penyinaran 3 detik, pemberian filter mampu menambah 4 step yang dapat dilihat oleh mata sedangkan satu step lainnya yaitu ketebalan $0,18 \mathrm{~cm}$ tidak nampak. Hal ini menunjukkan pemberian 3 variasi filter masih kurang dalam mereduksi radiasi- $\gamma$. Intensitas radiasi yang 
melewati $\mathrm{Pb}$ dengan ketebalan tersebut masih tergolong besar sehingga intensitas yang diteruskan juga besar yang dapat menghitamkan film atau IP.

Gambar 3b. menunjukkan citra yang tergolong baik. Radiasi hambur yang dihasilkan relatif kecil daripada yang lain. Akan tetapi pada citra tersebut memiliki ketajaman yang rendah. Sedangkan Gambar 3d. memiliki ketajaman yang lebih baik akan tetapi radiasi hambur yang ditimbulkan paling besar. Gambar 3c. memiliki nilai kontras paling besar dari citra lain dan ketajaman citra yang cukup tinggi sehingga tepi dan bagian dari tiap step dapat dideteksi. Dengan demikian penambahan $\mathrm{Pb}$ sebagai filter yang optimal pada penyinaran 2 detik dalam menghasilkan kualitas citra yang baik terdapat pada penambahan 10 filter $\mathrm{Pb}$ dengan ketebalan $1,8 \mathrm{~cm}$.

Pemberian filter pada penyinaran 3 detik menghasilkan nilai kontras yang tergolong bagus pada semua variasi filter. Hal ini dapat diketahui dari gambar yang berwarna terang tiap step sehingga antara step dengan background dapat dibedakan. Gambar 4b. terlihat citra tiap step tidak nampak dengan jelas, yang artinya ketajaman dari citra tergolong sangat rendah karena tidak bisa membedakan antar step dengan background. Sedangkan Gambar 4d. memiliki ketajaman yang lebih baik dari gambar sebelumnya. Namun masih terlihat hamburan pada citra. Gambar 4c. merupakan citra yang paling bagus karena memiliki ketajaman yang paling tinggi dan kekaburan yang relatif kecil pada semua step. Dengan demikian filter yang optimal pada penyinaran 3 detik dalam menghasilkan kualitas citra yang baik terdapat pada penambahan 10 filter $\mathrm{Pb}$.

Selain itu filter yang optimal juga dapat dilihat dari nilai MGVseperti pada Tabel 2. Dan Tabel 3. Nilai MGV yang tinggi yang berarti penyerapan radiasi besar menghasilkan citra yang terang sehingga dapat dengan mudah untuk dibedakan antara background dengan objek. Hasil citra yang diperoleh nampak jelas dilihat oleh mata daripada penggunaan 9 dan 11 filter. Nilai kontras penyinaran 2 dan 3 detik dengan penambahan 10 filter dapat dilihat pada Tabel 4.

Tabel 4. Nilai Kontras Penambahan 9 Filter $\mathrm{Pb}$

\begin{tabular}{ccc}
\hline Tebal $(\mathrm{cm})$ & 2 detik & 3 detik \\
\hline 0,18 & & \\
0,9 & $(38,19 \pm 0,26)$ & $(2,18 \pm 0,10)$ \\
1,8 & $(63,97 \pm 0,044)$ & $(17,89 \pm 0,52)$ \\
2,7 & $(71,81 \pm 0,42)$ & $(67,39 \pm 0,076)$ \\
3,6 & $(93,19 \pm 0,14)$ & $(86,29 \pm 0,38)$ \\
4,5 & $(97,69 \pm 0,072)$ & $(89,95 \pm 0,33)$ \\
5,4 & $(102,26 \pm 0,68)$ & $(111,16 \pm 0,086)$ \\
\hline
\end{tabular}

Penelitian selanjutnya penentuan tebal $\mathrm{Pb}$ yang dapat menurunkan laju dosis agar setara dengan laju dosis yang digunakan pada penyinaran 1 detik yaitu 1,57 cGy/s. Penentuan laju dosis dilakukan dengan menyertakan harga $\mathrm{B}$. Berikut nilai $\mathrm{B}$ untuk bahan $\mathrm{Pb}$ dengan energy 1,24 MeV yang ditunjukkan melalui Gambar 5 . 


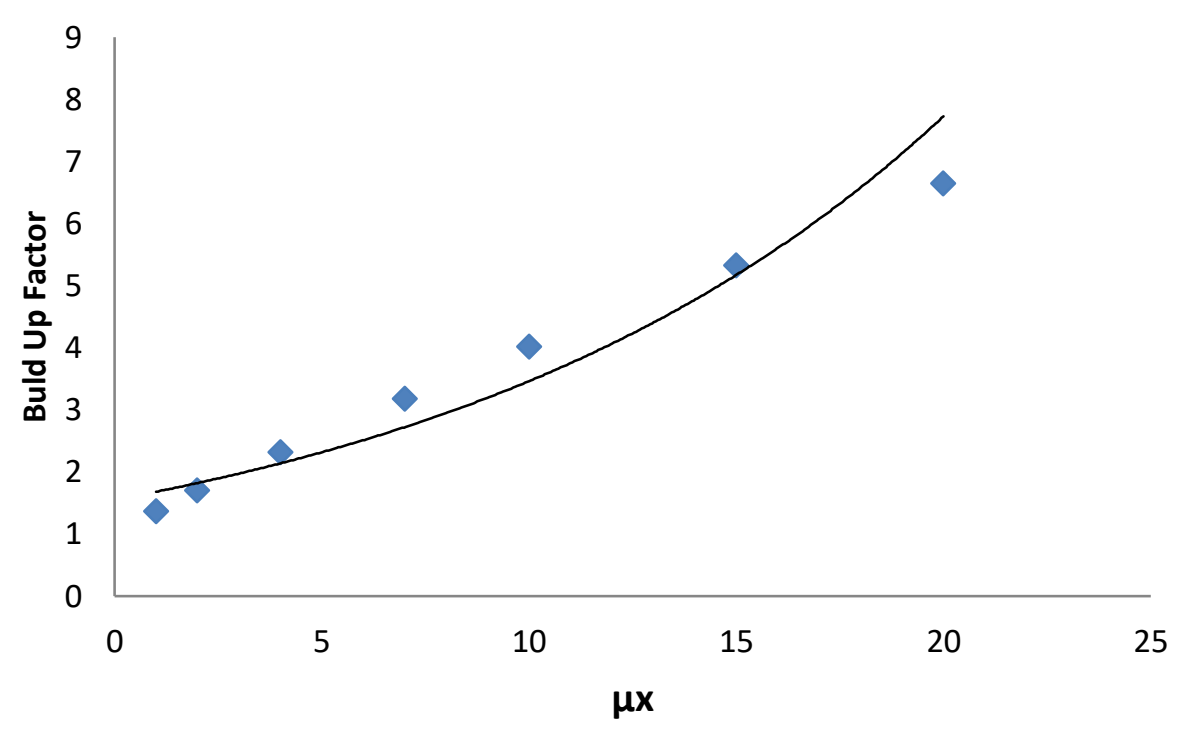

Gambar 5. Harga Build Up Factor

Berdasar Gambar 5. diperoleh persamaan fungsi $y=1,551 e^{0,08 x}$ dengan nilai $R^{2}=0,94$. Melalui persamaan tersebut dapat ditentukan nilai B dengan memasukkan hasil perkalian antara nilai koefisien atenuasi dan ketebalan $\mathrm{Pb}$. Koefisien $\mathrm{Pb}$ diperoleh dari hasil penelitian menggunakan Geiger Muller yaitu $0,212 / \mathrm{cm}$. Nilai B yang diperoleh kemudian digunakan untuk dapat menentukan nilai laju dosis pada masing- masing penyinaran. Berikut hasil laju dosis yang diperoleh dapat ditunjukkan melalui grafik hubungan laju dosis terhadap masingmasing ketebalan $\mathrm{Pb}$ seperti pada Gambar 6.

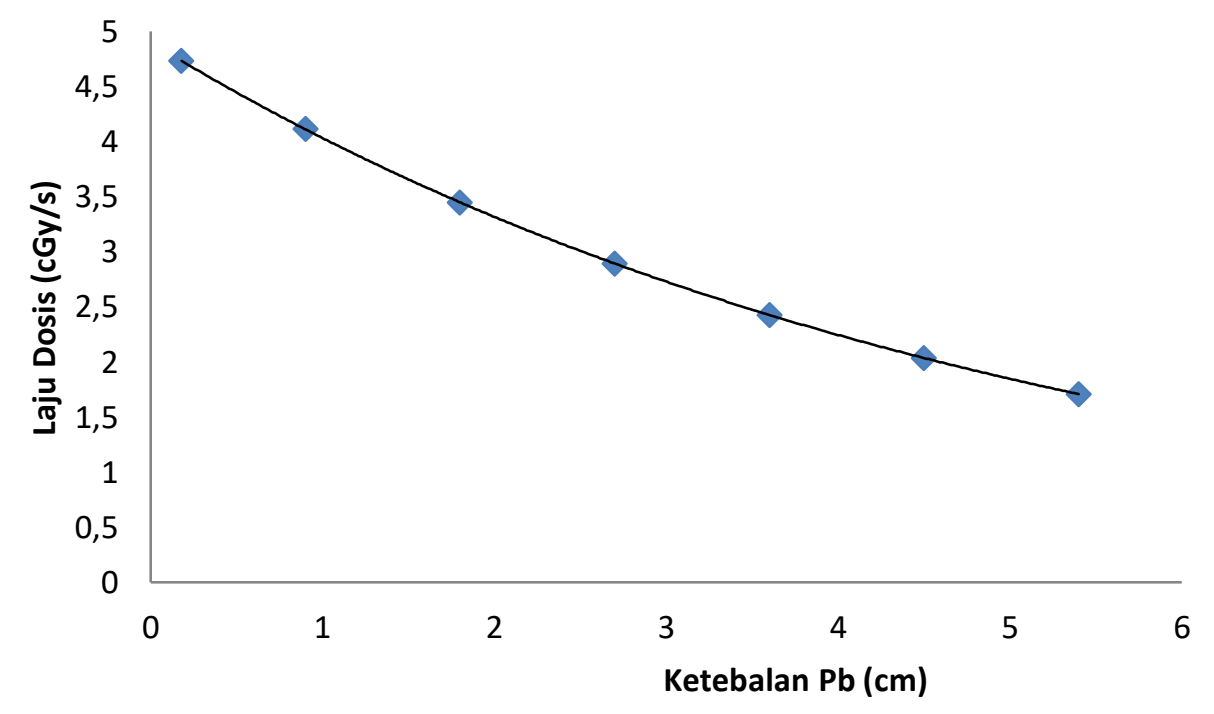

Gambar 6. Grafik Hubungan Laju Dosis terhadap masing-masing Ketebalan Pb pada Penyinaran 1 detik

Berdasar gambar tersebut dapat diketahui bahwa besarnya laju dosis setelah melalui bahan akan menurun secara eksponensial terhadap penambahan ketebalan $\mathrm{Pb}$. Hal ini berarti pelemahan laju dosis melalui proses penyerapan dalam bahan akan semakin besar pada 
ketebalan yang semakin besar pula. Pada grafik juga diperoleh persamaan eksponensial $y=$ $4,9 e^{-0,19 x}$ dengan nilai $R=1$. Melalui persamaan tersebut dapat digunakan untuk menentukan nilai laju dosis setelah melewati material $\mathrm{Pb}$ pada ketebalan tertentu.

Penentuan tebal $\mathrm{Pb}$ yang dapat digunakan untuk mereduksi laju dosis penyinaran hingga 1,57 cGy untuk penyinaran 1 detik dimulai dari 2,7 cm yang menghasilkan 1,45 cGy/s dengan nilai kontras $(49,77 \pm 0,095)$. Penyinaran 1 detik dengan tebal $\mathrm{Pb} 0,18 \mathrm{~cm}$ memperlihatkan warna yang gelap dengan nilai MGV dan kontras paling rendah yaitu masing-masing $(194,72$ $\pm 0,17) \mathrm{PSL} / \mathrm{mm}^{2}$ dan $(20,06 \pm 0,18)$. Laju dosis yang dihasilkannya pun besar yaitu 2,37 cGy/s. Sedangkan tebal $\mathrm{Pb} 0,9 \mathrm{~cm}$ dan $1,8 \mathrm{~cm}$ menampakkan warna yang cukup terang dan antara step tersebut dengan background dapat dibedakan oleh mata. Namun, pada ketebalan tersebut laju dosis yang dihasilkan masing-masing 2,06 cGy/s dan 1,72 cGy/s. Berdasar uraian tersebut maka penyinaran 1 detik dengan ketebalan $0,18 \mathrm{~cm}, 0,9 \mathrm{~cm}$ dan $1,8 \mathrm{~cm}$ tidak dapat digunakan untuk menurunkan laju dosis agar setara dengan $1,57 \mathrm{cGy} / \mathrm{s}$.

Penyinaran 2 detik tebal $\mathrm{Pb}$ yang dapat digunakan untuk menurunkan laju dosis dimulai dari 4,5 cm yang menghasilkan laju dosis $1,39 \mathrm{cGy} / \mathrm{s}$. Penyinaran 3 detik pada ketebalan maksimal yang digunakan yaitu $7,38 \mathrm{~cm}$ tidak mampu mereduksi radiasi- $\gamma$ agar setara dengan $1,57 \mathrm{cGy} / \mathrm{s}$ sehingga pada penyinaran tersebut tidak ada tebal $\mathrm{Pb}$ yang optimal. Berikut hasil laju dosis pada ketebalan tertentu pada penyinaran 2 dan 3 detik.

Tabel 5. Hasil Laju Dosis pada masing-masing Ketebalan

\begin{tabular}{cccc}
\hline \multicolumn{2}{c}{ Penyinaran 2 detik } & \multicolumn{2}{c}{ Penyinaran 3 detik } \\
\hline $\begin{array}{c}\text { Tebal } \\
(\mathrm{cm})\end{array}$ & $\begin{array}{c}\text { Laju Dosis } \\
(\mathrm{cGy} / \mathrm{s})\end{array}$ & $\begin{array}{c}\text { Tebal } \\
(\mathrm{cm})\end{array}$ & $\begin{array}{c}\text { Laju Dosis } \\
(\mathrm{cGy} / \mathrm{s})\end{array}$ \\
\hline 1,98 & 3,33 & 2,16 & 4,82 \\
2,7 & 2,74 & 2,88 & 4,90 \\
3,6 & 1,93 & 3,78 & 3,51 \\
4,5 & 1,36 & 4,68 & 2,95 \\
5,4 & 0,96 & 5,58 & 2,47 \\
6,3 & 0,67 & 6,48 & 2,07 \\
7,2 & 0,47 & 7,38 & 1,74 \\
\hline
\end{tabular}

\section{KESIMPULAN}

Penggunaan tebal $\mathrm{Pb}$ yang optimal dalam menghasilkan kualitas citra yang tinggi yaitu 1,8 $\mathrm{cm}$ pada penyinaran 2 dan 3 detik. Timbal yang dapat digunakan untuk menurunkan laju dosis setara $1,57 \mathrm{cGy} / \mathrm{s}$ dimulai dari ketebalan $2,7 \mathrm{~cm}$ untuk penyinaran 1 detik dan dimulai dari ketebalan $4,5 \mathrm{~cm}$ untuk penyinaran 2 detik

\section{SARAN}

Hasil penelitian di atas dapat dijadikan sebagai referensi untuk diterapkan pada phantom. Penelitian selanjutnya juga dapat dilakukan dengan dan tanpa grid, variasi luas lapangan serta diterapkan pada pesawat teleterapi sumber ${ }^{60} \mathrm{Co}$ yang memiliki aktivitas yang lebih besar.

\section{DAFTAR PUSTAKA}

Aprilina, Retno. (2018). Efek Area Kolimasi terhadap Dose Area Product (DAP) dan Kontras Radiograf pada General Radiography. Skripsi. FMIPA Universitas Jember.

Febriani, S. D. A. (2013). Optimalisasi Dosis Serap dan Kontras Radioraf dengan Permodelan 
Phantom Akrilik.Skripsi. Fisika FMIPA Universitas Jember

Khan, F.M., Gibbons, J. P. The Physics of Radiation Therapy Edition 5. Philadelphia USA: Lippincott Williams \& Wilkins

Kristiyanti, Santoso, B., Yuniarsari, L., Wiranto B.S. (2014). Penentuan Tebal Perisai Radiasi Perangkat Radioterapi Eksternal ${ }^{60}$ Co Untuk Posisi Penyinaran. Jurnal Forum Nuklir (JFN), 8 (2), 137-141.

Pardede,D. D. M., Setiawati, E. (2014).Perhitungan Nilai Dosis dan Kontras Citra Computed Radiography (CR) dengan Variasi Ketebalan dan Kombinasi Jenis Filter.Youngster Physics Journal, 3(4), 287-294

Rahma, I. N. (2016). Kajian dan Analisis Pelat Timbal(Pb) Bekas Tutup Instalasi Listrik pada Atap Rumah sebagai Bahan Proteksi Radiasi. Skripsi. Fisika FMIPA Universitas Negeri Semarang

Sparzinanda, E., Nehru., Nurhidayah. (2017). Pengaruh Faktor Eksposi Terhadap Kualitas Citra Radiografi. JOP, 3 (1), 14-22

Wahdayuni. (2017). Analisis Kualitas Gambar Radiografi dengan Merk Film yang Berbeda. Skripsi. Fakultas Sains dan Teknologi UIN Alauddin Makassar 